\title{
The effect of butter grains on physical properties of butter-like emulsions
}

\author{
Stine Rønholt, ${ }^{\star 1,2}$ Patrizia Buldo, $\dagger^{1,3}$ Kell Mortensen, $\neq$ Ulf Andersen, $\S$ Jes C. Knudsen, ${ }^{*}$ and Lars Wiking ${ }^{4}$ \\ *Department of Food Science, Faculty of Science, University of Copenhagen, Rolighedsvej 30, DK-1958 Frederiksberg C, Denmark \\ †Department of Food Science, Aarhus University, PO Box 50-8830 Tjele, Denmark \\ ¥Niels Bohr Institute, University of Copenhagen, Universitetsparken 5, 2100 Copenhagen Ø, Denmark \\ §Arla Strategic Innovation Centre Brabrand, Arla Foods, Rørdrumvej 2, 8220 Brabrand, Denmark
}

\begin{abstract}
Milk fat exists as globules in its natural state in milk. The potential of using globular fat to modulate the rheological properties and crystallization behavior in butter-like emulsions was studied in the present work. We conducted a comparative study of butter-like emulsions, with a fat phase consisting of $0,10,25,50$, or $100 \%$ anhydrous milk fat (AMF), the remaining fat being butter grains, and all samples containing $20 \%$ water, to obtain systematic variation in the ratio of globular fat. All emulsions were studied over 4 wk of storage at $5^{\circ} \mathrm{C}$. By combining small and large deformation rheology, we conducted a detailed characterization of the rheological behavior of butter-like emulsions. We applied differential scanning calorimetry to monitor thermal behavior, confocal laser scanning microscopy for microstructural analysis, and low-field pulsed nuclear magnetic resonance spectrometry to measure solid fat content. By combining these techniques, we determined that increasing the fraction of globular fat (by mixing with butter grains) decreases the hardness of butter-like emulsions up to an order of magnitude at $\mathrm{d} 1$. However, no difference was observed in thermal behavior as a function of butter grain content, as all emulsions containing butter grains revealed 2 endothermal peaks corresponding to the high $\left(32.7^{\circ} \mathrm{C} \pm 0.6\right)$ and medium $\left(14.6^{\circ} \mathrm{C} \pm 0.1\right)$ melting fractions of fatty acids. In terms of microstructure, decreasing the amount of butter grains in the emulsions resulted in formation of a denser fat crystal network, corresponding to increased hardness. Moreover, microstructural analysis revealed that the presence of butter grains resulted in faster formation of a continuous fat crystal network compared
\end{abstract}

Received August 5, 2013.

Accepted December 8, 2013.

${ }^{1}$ These authors contributed equally to this research.

${ }^{2}$ Current address: Department of Pharmacy, Faculty of Health and Medical Sciences, University of Copenhagen, Universitetsparken 2, DK-2100 Copenhagen Ø, Denmark.

${ }^{3}$ Current address: Department of Food Science, Faculty of Science, University of Copenhagen, Rolighedsvej 30, DK-1958 Frederiksberg C, Denmark.

${ }^{4}$ Corresponding author: lars.wiking@agrsci.dk with the $100 \%$ AMF sample, which was dominated by crystal clusters surrounded by liquid oil. During storage, hardness remained stable and no changes in thermal behavior were observed, despite an increase in solid fat content of up to $5 \%$. After $28 \mathrm{~d}$ of storage, we observed no difference in either microstructural or rheological properties, indicating that formation of primary bonds occurs primarily within the first day of storage. The rheological behavior of butter-like emulsions is not determined solely by hardness, but also by stiffness related to secondary bonds within the fat crystal network. The complex rheological behavior of milk fat-based emulsions is better characterized using multiple parameters.

Key words: milk fat, material science, butter grains, rheology

\section{INTRODUCTION}

Milk fat exists in its natural state as fat globules and is mainly composed of a triglyceride (TG) core surrounded by a complex protein membrane: the milk fat globule membrane. Anhydrous milk fat (AMF), consisting primarily of TG, is widely used in the food industry. Milk fat is characterized by an extreme diversity of FA, and thereby diverse TG composition, which induces a broad thermal range of melting transitions, ranging from $-40^{\circ} \mathrm{C}$ to $40^{\circ} \mathrm{C}$. The melting profile of milk fat is typically divided into 3 characteristic melting fractions: the low melting fraction with a melting point below $10^{\circ} \mathrm{C}$, the medium melting fraction, which melts from $10^{\circ} \mathrm{C}$ to $19^{\circ} \mathrm{C}$, and the high melting fraction, which melts above $20^{\circ} \mathrm{C}$ (Deffense, 1993). Despite the similar FA composition of nonemulsified bulk fat and emulsions such as natural cream (oil-in-water emulsion), their crystallization behavior differs (Walstra and Van Beresteyn, 1975; Fredrick et al., 2011). For fatbased systems, crystallization proceeds more slowly in oil-in-water emulsions compared with bulk fat because nucleation has to occur in each single globule. It has been argued that nucleation in intact and pure milk fat globules is presumably homogeneous, as the content of impurities is lower than in bulk fat and butter (Fredrick 
et al., 2011). Homogeneous nucleation requires more supercooling than heterogeneous nucleation, which therefore explains the slower crystallization process for emulsified fat. However, a previous study has reported a correlation between the size of milk fat globules and occurrence of heterogeneous nucleation behavior of TG (Michalski et al., 2004). Increasing the size of the milk fat globules increases the probability of having at least one catalytic impurity present within the milk fat globule, hence facilitating heterogeneous nucleation (Walstra, 2003). Moreover, the time needed to obtain the first nucleus catalyzing the crystallization process is inversely proportional to the size of the milk fat globules (Lopez et al., 2002, 2007). Another aspect to consider for butter-like emulsions is that the molecules located at the surface of the milk fat globules may induce crystallization of TG, conversely facilitating a faster crystallization process. Differences are reported in the complex and not yet fully understood crystallization mechanisms in bulk milk fat compared with emulsified fat (both oil-in-water and water-in-oil emulsions). However, the physical properties of the final crystallized products, as well as their final polymorphic crystal forms appear to be the same (Lopez et al., 2001a,b; Michalski et al., 2004; Rønholt et al., 2012).

The nucleation process and crystal growth are crucial for the fat crystal network, and consequently spreadability, mouthfeel, appearance, and product functionality (Mulder and Walstra, 1974). In addition, changing the amount of fat globules in milk fat-based products might influence product properties. Although of major industrial interest, the rheological response to the presence of fat globules within a continuous fat phase is documented in only a limited number of studies. It is generally accepted that the presence of fat globules decreases the hardness of the product compared with milk fat-based products without any fat globules present, because a crystalline intraglobular phase is formed rather than large bulk fat crystals (Mulder and Walstra, 1974; Juriaanse and Heertje, 1988; Buldo and Wiking, 2013). The microstructure of milk fat-based products (e.g., butter and butter blends) is very complex, due to a continuous fat crystal network interrupted by intact milk fat globules and water droplets, all dispersed in a continuous liquid fat phase (Juriaanse and Heertje, 1988; Buldo, 2013; Rønholt et al., 2013). When changing the ratio between the amounts of fat in the continuous phase versus fat within the fat globules, the microstructure changes accordingly and will likely affect the crystallization process, as discussed above; thus, microstructure formation and rheological properties within the system.

The fat crystal network is often characterized by the presence of irreversible strong bonds (e.g., as occurring due to mechanical interlinkage of the fat crystal upon crystal growth) and reversible weak bonds occurring via van der Waals interactions (van den Tempel, 1958). When applying a small stress, the crystal network may distort, resulting in reversible breakage of some crystal bonds. As the stress is removed, the crystal bonds will reform. In contrast, large stress will rearrange the network or cause fracturing, resulting in irreversible breaking of the bonds (Wright et al., 2001). The stress needed to break irreversible crystal-crystal interactions can be quantified by identification of the fracture point upon large deformation rheology, and the magnitude of this stress may in turn be linked to product hardness. The weak and reversible bonds are related to the elastic modulus of the material (Haighton, 1963). The rheological properties of milk fat are typically studied by using large or small deformation techniques. The rheological response to large deformations is highly nonlinear and involves breakdown of the material (Wright et al., 2001). In contrast, small deformations obtained within the linear region links material behavior to the applied deformation without breaking the structure of the product, characterizing the reversible, elastic bonds. As fat texture is a complex concept, it cannot be described with a single parameter (Mortensen and Danmark, 1982; Buldo, 2013). We therefore used both large deformation in the compression mode (stress at fracture) and small amplitude oscillation measurements (elastic modulus) using parallel plates to obtain a better rheological characterization of our emulsions.

The aim of this work was to elucidate how the presence of milk fat globules in a butter-like emulsion affects the crystallization process, microstructure formation, and thus rheological and textural properties. To do so, butter grains, containing both intact and partially damaged milk fat globules, were mixed in increasing amounts with AMF and water to form water-in-oil emulsions. The emulsions were stored at $5^{\circ} \mathrm{C}$ for $28 \mathrm{~d}$ and rheological and textural properties were monitored during storage. Furthermore, the crystallization behavior was studied using differential scanning calorimetry and linked to rheological properties as well as microstructure.

\section{MATERIALS AND METHODS}

\section{Materials}

Pasteurized cream with $38 \%$ fat (Arla Foods, Slagelse, Denmark) and AMF from Arla (Götene, Sweden) were used to prepare the emulsions. Sodium azide from Sigma Aldrich (St. Louis, MO) was added to the cream $(0.2 \mathrm{~g} / \mathrm{L})$ in all emulsions to prevent microbial growth. For the confocal laser scanning microscopy (CLSM) 
images, fluorescein-5-isothiocyanate (FITC; Merck, Darmstadt, Germany), Nile red, and 1,1'-dioctadecyl3,3,3',3'-tetramethyl-indodicarbocyanine perchlorate (D307); Molecular Probes, Life Technologies Europe BV, Taastrup, Denmark) were used.

\section{Preparation}

Five butter-like emulsions were prepared by mixing 10, 25, and 50\% AMF with butter grains; 0 (butter grains only) and $100 \%$ AMF samples were used as references. All butter-like emulsions, including the $100 \%$ AMF sample, were prepared with a water content of $20 \pm 2 \%$.

First, both the cream and AMF were held separately at $65^{\circ} \mathrm{C}$ for $15 \mathrm{~min}$ in a water bath to erase crystal history. Then, the cream was cooled at $7.5^{\circ} \mathrm{C} / \mathrm{min}$ to $10^{\circ} \mathrm{C}$ in ice bath $\left(-18 \pm 2^{\circ} \mathrm{C}\right)$ and incubated for $1 \mathrm{~h}$ at $5^{\circ} \mathrm{C}$. Sodium azide was added to the cream before churning it in a tabletop blender (CombiMax 600, Braun, Kronberg, Germany) at maximum speed. The blender was equipped with a 2.0-L mixing bowl and a universal chopper blade. The phase inversion was considered successful when the buttermilk visually separated from the butter grains. Thereafter, the butter grains were stored at $10^{\circ} \mathrm{C}$ for $2.5 \mathrm{~h}$. Afterward, AMF with a temperature of $40^{\circ} \mathrm{C}$ was mixed with the butter grains. The final water content of all butter-like emulsions, including the $100 \%$ AMF sample, was adjusted with excess buttermilk from the churning, aiming for $20 \%$ water. The $100 \%$ AMF sample was mixed under the same conditions used for the butter-like emulsions and stored in a refrigerator at $5^{\circ} \mathrm{C}$ for $28 \mathrm{~d}$. Analyses were run on d 1 , 7, 14, and 28 after production. Each emulsion, including the $100 \%$ AMF sample, was prepared in triplicate.

\section{Determination of Water Content}

The emulsions, including the $100 \%$ AMF sample, were placed in an oven at $100^{\circ} \mathrm{C}$ for $2 \mathrm{~h}$, and then placed in a desiccator at room temperature for $30 \mathrm{~min}$ to allow them to cool under a controlled environment. The water content was then determined as percentage water loss on drying, according to IDF provisional standard 26A (IDF, 1993). Measurements were performed in triplicate.

\section{Thermal Behavior}

The melting profiles of all emulsions were analyzed by a differential scanning calorimeter (Q 2000 DSC, TA Instruments, Hertfordshire, UK). Approximately 5 to $15 \mathrm{mg}$ of sample was placed at room tempera- ture $\left(21^{\circ} \mathrm{C}\right)$ into precooled aluminum pans $\left(5^{\circ} \mathrm{C}\right)$ and hermetically sealed. An empty, sealed pan was used as reference. The samples were heated from $5^{\circ} \mathrm{C}$ to $60^{\circ} \mathrm{C}$ at a rate of $5^{\circ} \mathrm{C} / \mathrm{min}$. The minimum peak of the endothermic fractions of the corresponding thermograms was determined. Differential scanning calorimetry analyses were performed at least in triplicate.

\section{Rheological Oscillation Measurements}

The mechanical characteristics were measured with $\mathrm{n}$ $=9$ per emulsion and sample, using a rheometer (AR G2, TA Instruments). The rheometer was equipped with temperature-controlled, serrated parallel plates (radius $25 \mathrm{~mm}$, TA Instruments). The serrated plate setup is considered the most suitable to characterize milk fatbased products (Rønholt et al., 2014b). Briefly, the samples were prepared by gently punching a precooled metallic cylinder (radius $25 \mathrm{~mm}$ ) into the emulsions, including the 100\% AMF sample. The sample cylinder was then cut into disks with a height of $4 \mathrm{~mm}$ using a wire cutter (Rønholt et al., 2014b). Measurements were made at $5^{\circ} \mathrm{C}$, using frequency sweeps in intervals of 500 to $0.05 \mathrm{rad} / \mathrm{s}$, with a constant oscillation stress of $500 \mathrm{~Pa}$. All measurements were within the linear viscoelastic region (data not shown).

\section{Large Deformation Rheology}

Large deformation rheology was performed using a texture analyzer (Instron 6654, Instron Inc., Norwood, MA) equipped with parallel plates $(70 \mathrm{~mm}$ in diameter). Cylindrical butter samples were prepared with a radius of $15 \mathrm{~mm}$ and cut with a wire cutter to a height of $15 \mathrm{~mm}$. To avoid any melting, the samples were refrigerated $\left(5^{\circ} \mathrm{C}\right)$ until analyzed. The compression test was performed at $50 \mathrm{~mm} / \mathrm{min}$, and the sample was compressed to $50 \%$ of its height.

\section{Solid Fat Content}

Solid fat content (SFC) was measured in all emulsions, including the $100 \%$ AMF sample, after 1, 7, 14, and $28 \mathrm{~d}$ of production. The measurements were carried out at $5^{\circ} \mathrm{C}$ with a low-field pulsed nuclear magnetic resonance spectrometer (p-NMR, Resonance Maran Ultra; Oxford Instruments, Oxfordshire, UK), by using direct measurements; results were an average of at least 4 replicates. As the SFC obtained is the solid fat content relative to the amount of liquid (water and oil) in the samples, the SFC data reported in the present work were corrected for the amount of water, as described by Rønholt et al. (2014c). 


\section{Microstructure Analysis}

The CLSM images were captured using an inverted Leica confocal scanning laser microscope (SP5; Leica Microemulsions, Wetzlar GmbH, Wetzlar, Germany), operated at room temperature. Nile red, D307, and FITC were used as the florescence stain agents for liquid fats, phospholipids, and proteins, respectively. Nile red and FITC were dissolved in acetone to a final concentration of $0.01 \%$, whereas D307 was dissolved in ethanol, also to a $0.01 \%$ concentration. Suitable amounts of the dye solutions were placed on a precooled glass slide $\left(5^{\circ} \mathrm{C}\right)$, allowing the solvents to evaporate before adding the sample. Hereafter, the samples were stored at $5^{\circ} \mathrm{C}$ for $1 \mathrm{~h}$, before microstructural analysis, according to Buldo and Wiking (2012). Argon/ArKr $488 \mathrm{~nm}$, HeNe $543 \mathrm{~nm}$, and HeNe $633 \mathrm{~nm}$ laser lines were used for excitation to induce fluorescence emission. A $63 \times$ magnification water immersion objective was used to acquire images.

\section{Statistical Analysis}

All data were analyzed by 2-way ANOVA using SAS software (version 9.3 SAS Institute Inc., Cary, NC). Data are reported as least squares means and error bars reflect standard error as calculated using SAS software, unless otherwise stated.

\section{RESULTS AND DISCUSSION}

\section{Effect of Butter Grains on Microstructure of Butter-Like Emulsions}

Representative images of the emulsion microstructure captured using confocal laser scanning microscopy are shown in Figure 1. In the images, the red spherical areas represent the liquid oil, the green areas are the water and protein phase, and the blue areas represent the phospholipids. The gray shadows in the images indicate the fat crystal network, as previously described by Buldo and Wiking (2012). The water content of the emulsions was measured on all days of analysis, showing an average water content of $20 \% \pm 2 \%$ during the $28 \mathrm{~d}$ of storage.

Butter grains were mixed with AMF to study the potential of using milk fat globules to manipulate the properties of butter-like emulsions. From Figure 1, our hypothesis is visually confirmed, because a fraction of more or less intact fat globules was observed as bright red, circular objects. At d 1, the 0\% AMF emulsion contained the highest fraction of milk fat globules of the emulsions studied. When the percentage of AMF was increased, the fraction of milk fat globules decreased accordingly. As seen in Figure 1, the butter grains consisted of intact milk fat globules and water droplets surrounded by a partially crystalline continuous milk fat phase. Additionally, components originating from the milk globule, such as phospholipids, were observed.

In more detail, d 1 emulsions containing 25 and $50 \%$ AMF had the densest crystalline network (i.e., presence of more black shadows) compared with the 0 and $10 \%$ AMF emulsions. The crystal clusters present in the 100\% AMF had more liquid oil present around the dark shadows, and a dense continuous crystal network was therefore not visible. For the $0 \%$ AMF emulsion, the amount of continuous liquid fat phase was limited, and a continuous fat crystal network was not yet developed at $d 1$. During storage, the fat crystal network in the $100 \%$ AMF sample became denser (Figure 1). No changes in crystal network, and therefore microstructure, were observed during storage from 1 to $14 \mathrm{~d}$ for the 0 to $50 \%$ AMF emulsions (Figure 1). After 28 $\mathrm{d}$ of storage, larger crystal clusters were observed in all emulsions, including the 100\% AMF sample.

The SFC was significantly affected $(P<0.001)$ by both the percentage of AMF and days of storage (from d 1 to 14). The level of SFC increased during the first $14 \mathrm{~d}$ of storage (Figure 2), but no significant change in SFC was observed beyond d 14. However, the increase in SFC from d 1 to 14 did not affect the microstructure of emulsions containing butter grains $(0-50 \%$ butterlike emulsions), as crystallization continued inside the globules. When no fat globules were present, as for the $100 \%$ AMF sample, crystallization occurred in the continuous fat phase; therefore, larger crystal clusters were formed. Mixing AMF with butter grains significantly decreased the SFC (Figure 2). The 0\% AMF emulsion had a significantly higher SFC compared with the other emulsions, including the $100 \%$ AMF sample, at all storage times studied. It could be speculated that mixing $\mathrm{AMF}$, incubated at $40^{\circ} \mathrm{C}$, and butter grains, incubated at $10^{\circ} \mathrm{C}$, might have caused partial melting of the TG within the milk fat globules and continuous fat phase in the butter grains. Such partial melting would likely have changed the crystallization process and crystal growth and would therefore explain the significantly higher SFC of the 0\% AMF emulsion compared with the other emulsions. However, upon storage, the emulsions were exposed to supercooling and TG eventually melted upon mixing recrystallized. As seen in Figure 2 , SFC stabilized after $14 \mathrm{~d}$ of subsequent storage. The $0 \%$ AMF emulsion was characterized by the highest SFC among the emulsions studied. Moreover, no difference in thermal behavior was observed between the emulsions after $28 \mathrm{~d}$ of storage.

As described earlier, the nucleation process occurring in intact milk fat globules is expected to be ho- 


\section{$0 \%$}

1

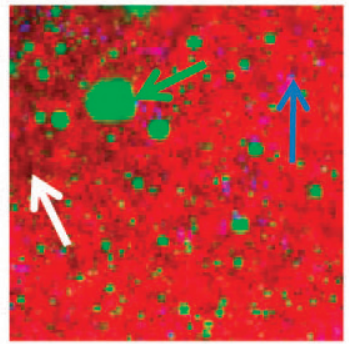

7
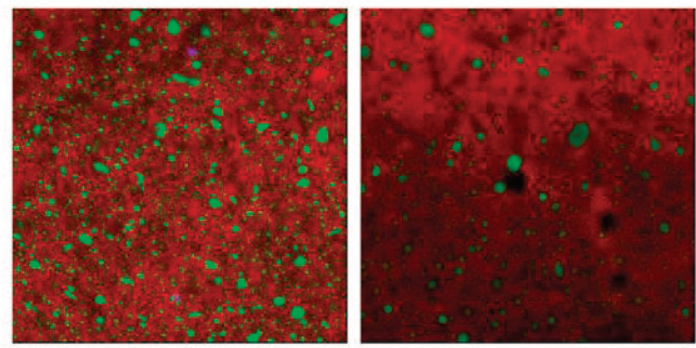

1

4
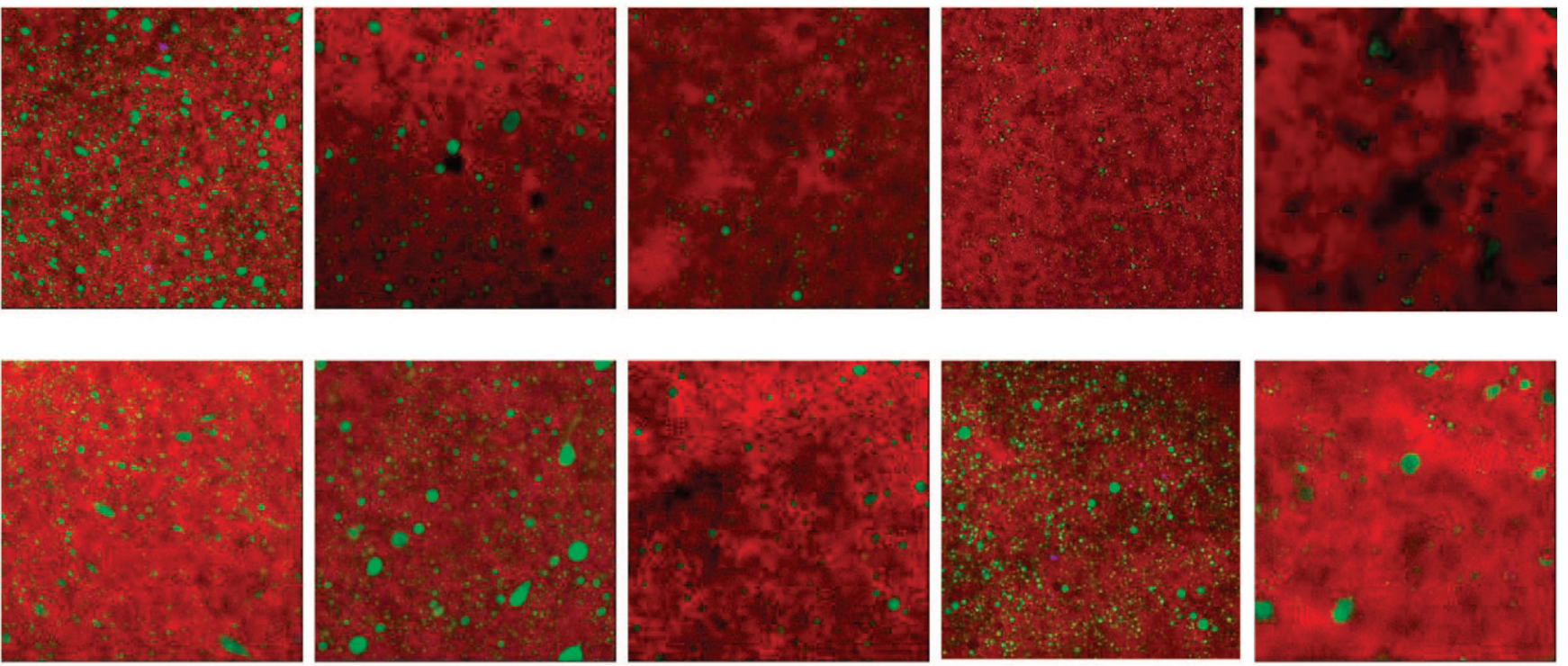

2

8
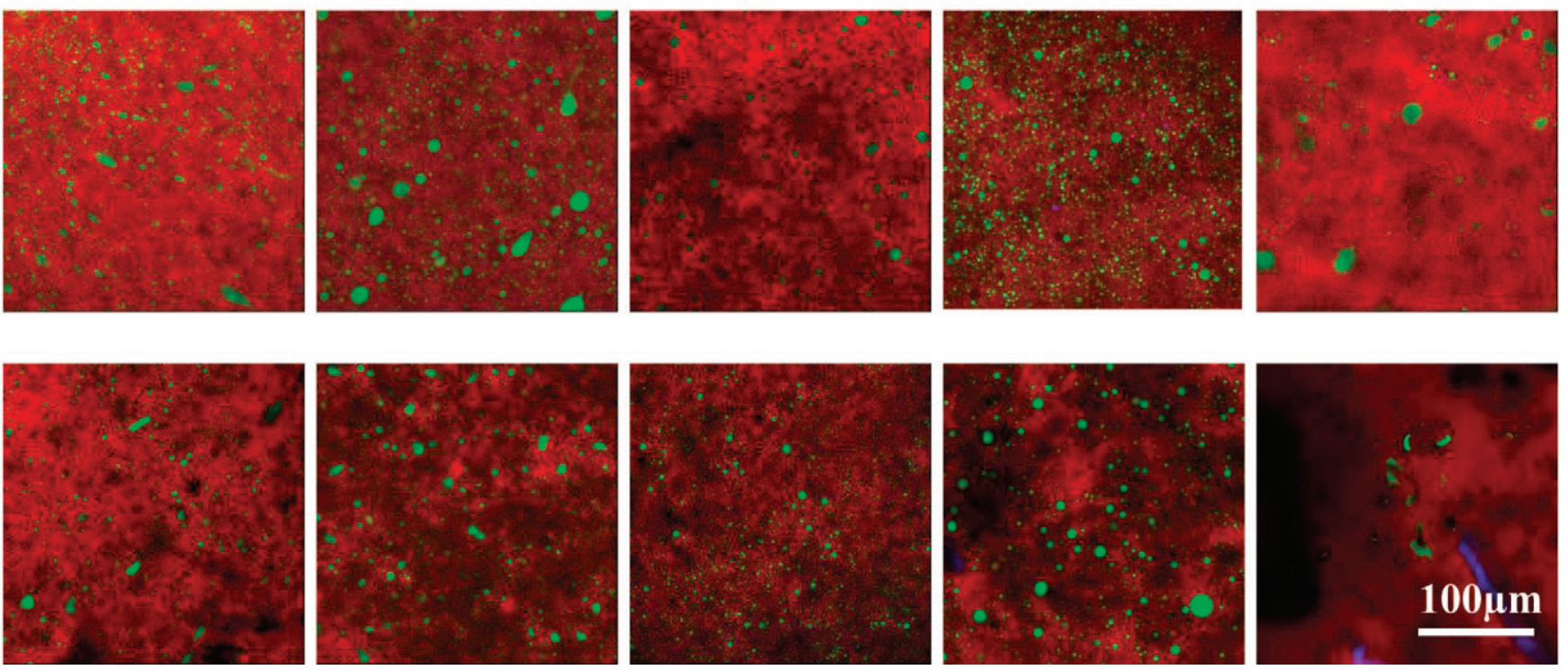

Figure 1. Confocal laser scanning microscopy images of butter-like emulsions containing butter grains mixed with 10,25 , or $50 \%$ anhydrous milk fat (AMF), respectively; 0 and $100 \%$ AMF were used as references. Images were captured after 1, 7, 14, and $28 \mathrm{~d}$ of storage. The black-gray nonspherical shadows on the image background (white arrow) represent the crystal network of the emulsions. The red areas indicate the liquid fat of the emulsion, the green areas (green arrow) indicate protein or water phases and blue the phospholipids (blue arrow).

mogeneous, whereas the crystallization process in the continuous fat phase surrounding the milk fat globules and butter grains is dominated by the faster heterogeneous crystallization. Upon phase inversion of the cream, when forming the butter grains, new interfaces are formed that act as catalytic impurities, causing heterogeneous nucleation (Rønholt et al., 2013). When the amount of butter grains is increased, the amount of new interfaces also increases, facilitating formation of a more dense fat crystal network (Rønholt et al., 2012).
In terms of microstructure, the 0 to $25 \%$ AMF emulsions had similar crystal networks composed of small crystal clusters forming a continuous crystal network (Figure 1). Unlike the 0 to $25 \%$ butter-like emulsions, the 50 and $100 \%$ AMF contained larger crystal clusters, and thus formed a network with fewer contact points between the crystals (Figure 1). Based on this observation, we concluded that presence of a greater amount of butter grains in the emulsions (0-25\% AMF emulsions) led to a continuous crystal network in the continuous 


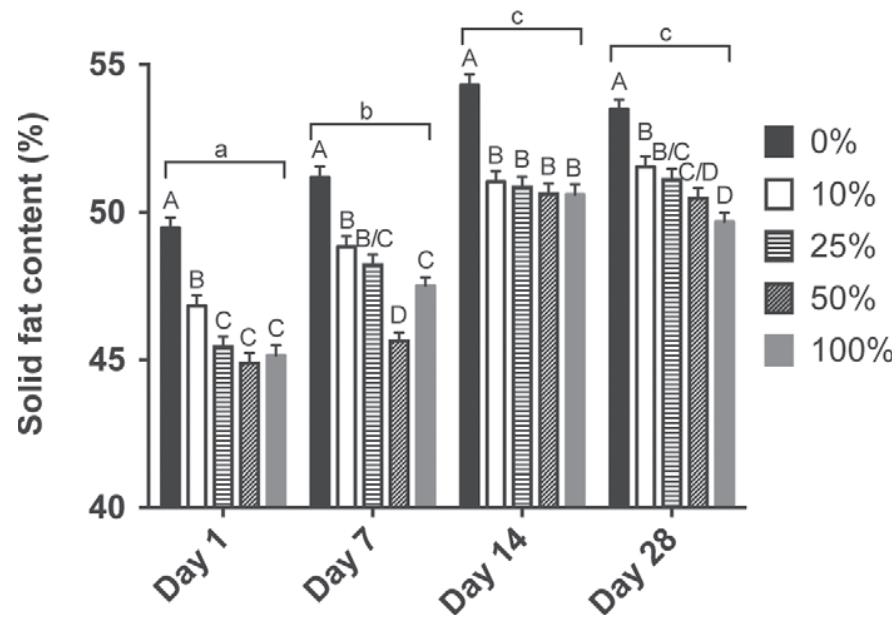

Figure 2. Level of solid fat content (SFC; \%) after 1, 7, 14, and 28 d of storage at $5^{\circ} \mathrm{C}$, measured by pulsed nuclear magnetic resonance. The butter-like emulsions contain butter grains mixed with 10, 25 , and 50\% anhydrous milk fat (AMF), respectively; 0 and 100\% AMF were used as references. The SFC values refer to the amount of solid fat relative to liquid oil. The error bars represent the standard error. Lowercase letters indicate difference between days of measurement; uppercase letters indicate differences between samples within the same day of measurement.

phase. In contrast, when a limited amount or no fat globules were present (e.g., 50 and 100\% AMF emulsions) in the sample, the crystals and crystal clusters either did not form a continuous network (e.g., 100\% $\mathrm{AMF}$ at d 1) or they formed larger aggregates (e.g., 50 and $100 \%$ AMF during storage).

In conclusion, the presence of butter grains in the emulsions accelerated the formation of a continuous crystal network. Moreover, smaller crystal clusters were formed in the presence of butter grains, thus forming a network with more contact points. Contrary, a crystal network with fewer contact points was formed in emulsions with limited or no fat globules because of the large amount of liquid fat in the continuous phase.

\section{Effect of Butter Grains on Melting Behavior of Butter-Like Emulsions}

The melting behavior of the different butter-like emulsions was studied using differential scanning calorimetry and p-NMR. The thermograms of the butter-like emulsions containing butter grains showed 2 melting fractions. The first medium melting fraction (MMF), with an average melting point of $14.6^{\circ} \mathrm{C} \pm 0.1$, was relatively sharp and ended at $20^{\circ} \mathrm{C}$, corresponding to previous observations in milk fat-based products by ten Grotenhuis et al. (1999). The endothermic peak in the MMF was then followed by a broad shoulder, ending with a second endothermal peak in the range of high melting fraction (HMF), with an average melting point of $32.7^{\circ} \mathrm{C} \pm 0.6$ (Figure 3, peak values listed in Table 1). The HMF peak was broad compared with the peak corresponding to HMF in the $100 \%$ AMF sample. Such peak broadening is a result of the complex chemical composition of natural milk fat. Due to the high number of FA present in milk fat, multiple thermal events occur within each melting fraction. Such multiple thermal transitions cause partial overlapping peaks, seen in the thermogram as peak broadening (Lopez et al., 2007). Similar broad peaks within the HMF were previously observed for both commercial butters (Tomaszewska-Gras, 2012) and milk fat (ten Grotenhuis et al., 1999), analyzed in the temperature range from -40 to $50^{\circ} \mathrm{C}$ (Tomaszewska-Gras, 2012) and -65 to $70^{\circ} \mathrm{C}$ (ten Grotenhuis et al., 1999) respectively, both using a scan rate of $5^{\circ} \mathrm{C}^{-1}$.

The $100 \%$ AMF sample showed the typical thermogram of milk fat (ten Grotenhuis et al., 1999; Lopez et al., 2007), containing an extra melting fraction in the range of the $\mathrm{HMF}$ in the range of $23.3^{\circ} \mathrm{C} \pm 0.06$ (Figure 3), compared with the emulsions. Moreover, the $\operatorname{MMF}\left(15.7^{\circ} \mathrm{C} \pm 0.08\right)$ and $\operatorname{HMF}\left(37.7^{\circ} \mathrm{C} \pm 8\right)$ values of the $100 \%$ AMF sample were higher compared with the emulsions containing butter grains. The temperature of the minimum peak for both the MMF and HMF was lower for the 0 to $50 \%$ AMF emulsions compared with the $100 \%$ AMF sample (Figure 3 ). The decrease in temperature of the minimum peak occurring in the emulsified fat is likely caused by the presence of phospholipids and other minor components present in the milk fat globule membrane (Wright et al., 2000). In addition to

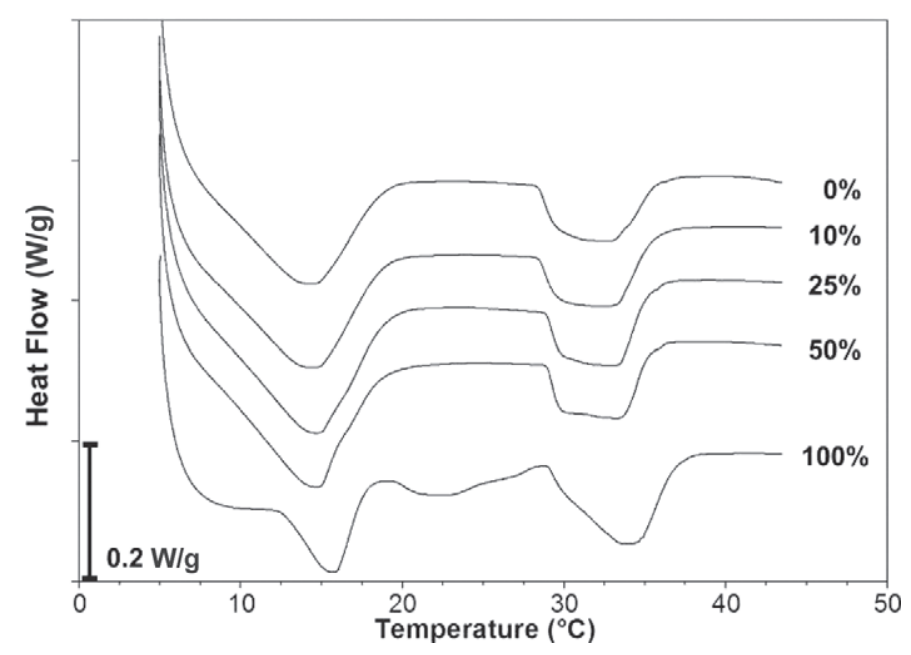

Figure 3. Thermogram of butter-like emulsions containing butter grains mixed with 10, 25, and 50\% anhydrous milk fat (AMF), respectively; 0 and $100 \%$ AMF were used as references. The thermogram was obtained after $28 \mathrm{~d}$ of storage at $5^{\circ} \mathrm{C}$; no difference was observed as a function of time (Table 1 ). The heating rate was $5^{\circ} \mathrm{C} / \mathrm{min}$. The endothermic reactions are seen as valleys. 
Table 1. Melting point (mean $\pm \mathrm{SE}$ ) of the medium melting fraction (MMF) and high melting fractions (HMF) of butter-like emulsions and $100 \%$ AMF analyzed after 1, 7, 14, and $28 \mathrm{~d}$ of storage

\begin{tabular}{|c|c|c|c|c|}
\hline Batch $^{1}$ & Day $^{2}$ & $\operatorname{MMF}\left({ }^{\circ} \mathrm{C}\right)$ & $\mathrm{HMF}_{\text {low }}{ }^{3}\left({ }^{\circ} \mathrm{C}\right)$ & $\operatorname{HMF}\left({ }^{\circ} \mathrm{C}\right)$ \\
\hline $0 \%$ & 1 & $14.47 \pm 0.01^{\mathrm{A}, \mathrm{ab}}$ & & $32.47 \pm 0.12^{\mathrm{A}, \mathrm{a}}$ \\
\hline $10 \%$ & & $14.46 \pm 0.03^{\mathrm{A}, \mathrm{ab}}$ & & $32.56 \pm 0.38^{\mathrm{A}, \mathrm{a}}$ \\
\hline $25 \%$ & & $14.65 \pm 0.13^{\mathrm{A}, \mathrm{ab}}$ & & $32.99 \pm 0.27^{\mathrm{A}, \mathrm{a}}$ \\
\hline $50 \%$ & & $14.65 \pm 0.04^{\mathrm{A}, \mathrm{ab}}$ & & $33.32 \pm 0.12^{\mathrm{A}, \mathrm{a}}$ \\
\hline $100 \%$ & & $15.76 \pm 0.06^{\mathrm{B}, \mathrm{ab}}$ & $23.71 \pm 0.06^{\mathrm{a}}$ & $34.52 \pm 0.11^{\mathrm{B}, \mathrm{a}}$ \\
\hline $0 \%$ & 7 & $14.52 \pm 0.04^{\mathrm{A}, \mathrm{a}}$ & & $31.6 \pm 0.48^{\mathrm{A}, \mathrm{b}}$ \\
\hline $10 \%$ & & $14.50 \pm 0.11^{\mathrm{A}, \mathrm{a}}$ & & $31.65 \pm 0.53^{\mathrm{A}, \mathrm{b}}$ \\
\hline $25 \%$ & & $14.63 \pm 0.08^{\mathrm{AB}, \mathrm{a}}$ & & $32.9 \pm 0.36^{\mathrm{A}, \mathrm{b}}$ \\
\hline $50 \%$ & & $14.84 \pm 0.04^{\mathrm{B}, \mathrm{a}}$ & & $33.44 \pm 0.17^{\mathrm{BC}, \mathrm{b}}$ \\
\hline $100 \%$ & & $15.71 \pm 0.17^{\mathrm{C}, \mathrm{a}}$ & $23.28 \pm 0.30^{\mathrm{a}}$ & $33.75 \pm 0.44^{\mathrm{C}, \mathrm{b}}$ \\
\hline $0 \%$ & 14 & $14.43 \pm 0.06^{\mathrm{A}, \mathrm{ab}}$ & & $32.24 \pm 0.13^{\mathrm{AB}, \mathrm{ab}}$ \\
\hline $10 \%$ & & $14.47 \pm 0.14^{\mathrm{AB}, \mathrm{ab}}$ & & $32.18 \pm 0.14^{\mathrm{A}, \mathrm{ab}}$ \\
\hline $25 \%$ & & $14.61 \pm 0.03^{\mathrm{AB}, \mathrm{ab}}$ & & $32.64 \pm 0.34^{\mathrm{AB}, \mathrm{ab}}$ \\
\hline $50 \%$ & & $14.71 \pm 0.01^{\mathrm{B}, \mathrm{ab}}$ & & $33.13 \pm 0.03^{\mathrm{B}, \mathrm{ab}}$ \\
\hline $100 \%$ & & $15.6 \pm 0.10^{\mathrm{C}, \mathrm{ab}}$ & $23.48 \pm 0.23^{\mathrm{a}}$ & $34.49 \pm 0.05^{\mathrm{C}, \mathrm{ab}}$ \\
\hline $0 \%$ & 28 & $14.38 \pm 0.08^{\mathrm{A}, \mathrm{b}}$ & & $32.05 \pm 0.45^{\mathrm{A}, \mathrm{ab}}$ \\
\hline $10 \%$ & & $14.46 \pm 0.07^{\mathrm{AB}, \mathrm{b}}$ & & $32.98 \pm 0.36^{\mathrm{B}, \mathrm{ab}}$ \\
\hline $25 \%$ & & $14.6 \pm 0.05^{\mathrm{AB}, \mathrm{b}}$ & & $33.14 \pm 0.20^{\mathrm{BC}, \mathrm{ab}}$ \\
\hline $50 \%$ & & $14.7 \pm 0.01^{\mathrm{B}, \mathrm{b}}$ & & $33.35 \pm 0.03^{\mathrm{BC}, \mathrm{ab}}$ \\
\hline $100 \%$ & & $15.6 \pm 0.05^{\mathrm{C}, \mathrm{b}}$ & $22.67 \pm 0.12^{\mathrm{b}}$ & $33.99 \pm 0.08^{\mathrm{C}, \mathrm{ab}}$ \\
\hline
\end{tabular}

${ }^{\mathrm{A}-\mathrm{C}}$ Means with different uppercase superscripts differ between samples within the same day of measurement $(P<0.05)$.

${ }^{\mathrm{a}, \mathrm{b}}$ Means with different lowercase superscripts differ between days of measurement $(P<0.05)$.

${ }^{1}$ Batch: butter grains mixed with 10,25 , or $50 \%$ anhydrous milk fat (AMF); $0 \%$ AMF and $100 \%$ AMF were used as references.

${ }^{2}$ Days of storage at $5^{\circ} \mathrm{C}$.

${ }^{3} \mathrm{HMF}_{\text {low }}=$ the low melting points in the HMF range.

the MMF and HMF described, an exothermic peak was present in the $100 \%$ AMF sample at $18^{\circ} \mathrm{C}$. A previous study has reported on a similar exothermic event in milk fat starting at $19^{\circ} \mathrm{C}$ and ending at $23^{\circ} \mathrm{C}$, occurring after isothermal crystallization at $10^{\circ} \mathrm{C}$, presumably related to formation of $\beta^{\prime}$-crystals directly from the melt (ten Grotenhuis et al., 1999).

When we compared the emulsions containing increasing levels of butter grains, we observed no systematic variation in peak values (Table 1 ). We assume that the melting behavior of the butter-like emulsions was not affected by mixing with up to $50 \%$ of AMF. Likewise, storage did not reveal any effect on the melting behavior of the butter-like emulsions (Figure 3).

\section{Effect of Fat Globules on Rheological Properties of Butter-Like Emulsions}

The elastic modulus at a frequency of $5 \mathrm{rad} / \mathrm{s}$ (Figure 4) characterizes the stiffness of the microstructure of the various emulsions, which is an indicator of the development of secondary bonds in the emulsions. Overall, the elastic modulus was significantly affected by the amount of $\operatorname{AMF}(P<0.001)$ but not by days of storage; however, a strong interaction was found between storage and amount of $\operatorname{AMF}(P<0.001$; Figure 4$)$. The greatest effect of AMF was found at $d 1$, where $0 \%$
AMF had an elastic modulus almost 2 times higher than the samples without butter grains (100\% AMF; Figure 4). A corresponding difference in SFC was observed between the $0 \%$ AMF emulsion and 100\% AMF sample, with $0 \%$ AMF having a 5\% higher SFC (Figure 2). Likewise, the microstructure for the 100\% AMF sample showed a noncontinuous fat crystal network (Figure 1). In contrast, when comparing emulsions containing an increasing fraction of fat globules $(50,25$, and $10 \%$ $\mathrm{AMF}$ ), those with fewer fat globules (e.g., 50\% AMF emulsion) had the highest elastic modulus, which was 1.7 times higher than the product containing more fat globules (e.g., 10\% AMF emulsion). These findings are in agreement with the microstructural images from $\mathrm{d} 1$ (Figure 1), where the 50\% AMF emulsion had the densest fat crystal network, corresponding to a high elastic modulus. It is generally accepted that the number of crystal-crystal interactions is strongly related to the rheological properties of lipid-based materials (Herrera and Hartel, 2000). At d 1, however, the level of SFC was not directly related to hardness of the 0 to $50 \%$ AMF emulsions.

During storage, the initially observed difference in the elastic modulus between emulsions was diminished. After $28 \mathrm{~d}$ of storage at $5^{\circ} \mathrm{C}$, all butter-like emulsions, including the $100 \%$ AMF sample, had the same elastic modulus (Figure 4) and an SFC differing by less 


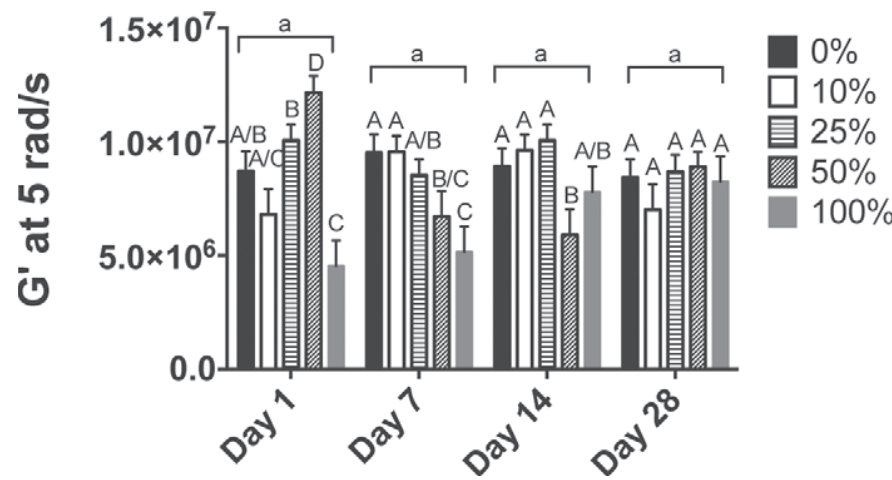

Figure 4. Elastic modulus, $\mathrm{G}^{\prime}(\mathrm{Pa})$, (at $5 \mathrm{rad} / \mathrm{s}$ ) of butter-like emulsions after $1,7,14$, and $28 \mathrm{~d}$ of storage. Emulsions were made from butter grains mixed with 10,25 , and $50 \%$ anhydrous milk fat (AMF), respectively; 0 and $100 \%$ AMF were used as references. The error bars represent the standard error. Lowercase letters indicate difference between days of measurement; uppercase letters indicate differences between samples within the same day of measurement.

than $5 \%$. Moreover, no difference in microstructure was observed in the CLSM images after $28 \mathrm{~d}$ of storage. The strong statistical interaction was shown by the significant increase $(P<0.05)$ in elastic modulus for the $100 \%$ AMF-based sample during storage, whereas the elastic modulus of the 0 to $50 \%$ butter-like emulsions was unaffected when compared at $\mathrm{d} 1$ and 28 (Figure 4). A stable elastic modulus of milk fat-based emulsions during storage has been observed in 2 recent studies, where wide variation was observed for both small and large deformation measurements during storage (Pothiraj et al., 2012; Rønholt et al., 2014c). Alexa et al. (2010) observed an increase in the elastic modulus during $15 \mathrm{~d}$ of storage at $6^{\circ} \mathrm{C}$ in margarine (60\% oil phase and $40 \%$ water). As only the $100 \%$ AMF sample increased in elastic modulus as a function of time, corresponding to formation of a continuous fat crystal network as seen in the CLSM images (Figure 1 ), we speculate that the presence of butter grains led to faster stabilization of the network.

\section{Effect of Fat Globules on Textural Properties of Butter-Like Emulsions}

In addition to the elastic modulus discussed above, hardness of the emulsions was characterized by the stress at fracture obtained by the compression test (Figure 5). Overall, increasing the amount of butter grains decreased the stress at fracture. At $d 1$, the stress at fracture was approximately 1 order of magnitude higher for the 25 to $100 \%$ AMF than for the 0 and $10 \%$ AMF emulsions (Figure 5). In a recent study, it was demonstrated that presence of fat globules in milk fat-based emulsions decreases the hardness of the emulsions, whereas a higher volume fraction of the continuous fat phase increases the hardness of milk fat-based products (Buldo, 2013). In presence of butter grains (i.e., 0 and $10 \% \mathrm{AMF}$ ), more and smaller crystals were formed in the continuous phase, resulting in a high SFC and thus more contact points than in the $100 \%$ AMF. This corresponded to greater stiffness and lower hardness (Figures 4 and 5). For the 0 to 50\% AMF emulsions, a correlation was observed between increasing elastic modulus and increasing stress at fracture. For the $100 \%$ AMF sample, however, no such relationship was observed. Here, a low elastic modulus was seen complementary to high stress at fracture, meaning that the product was hard without being stiff. Similarly, it has been shown for puff pastry butter that a milk fat-based product can be characterized simultaneously by low strain at fracture and high elastic modulus (Rønholt et al., 2014a). This indicates that several elements contribute to textural properties of emulsions, because the hardness of emulsions is influenced not only by crystal size (and thus by the number of contact points) but also by the amount of butter grains and the strength of the bonds (Buldo, 2013). By increasing the amount of AMF in the emulsion from 0 to $100 \%$, the hardness increased (Figure 5). Therefore, by reducing the amount of butter grains, a denser crystal network with stronger primary bonds was formed (Figure 5). During storage, hardness was constant in all emulsions including $100 \%$ AMF (Figure 5), indicating that formation of primary bonds occurs during the first day of storage. However, over a prolonged storage time (e.g., $60 \mathrm{~d})$, postcrystallization events occur, leading to further development of the fat crystal network and thus to an increase in hardness (Alexa et al., 2010).

Changing the ratio between butter grains and AMF can be used as a tool to alter the stress at fracture and the hardness of emulsions. The difference in stress at fracture and hardness of the butter-like emulsions remains during $28 \mathrm{~d}$ of isothermal storage at $5^{\circ} \mathrm{C}$. However, the stiffness measured using the elastic modulus, thermal behavior, and microstructure is not affected by changes in the ratio between butter grains and AMF. Generally, the presence of butter grains, containing milk fat globules, leads to faster formation of a continuous fat crystal network. This is presumably due to the catalytic effect of the milk fat globule membrane on crystallization. The elastic modulus of the various emulsions decreased by an order of magnitude when the amount of butter grains was decreased (from 0 to $10 \% \mathrm{AMF}$ to $\geq 25 \% \mathrm{AMF}$ ). Based on the techniques used, we concluded that the level of SFC and melting behavior were not good descriptors of the rheological and textural properties of butter-like emulsions. The combination of uniaxial compression test and oscillation rheology allowed us, however, to characterize the 


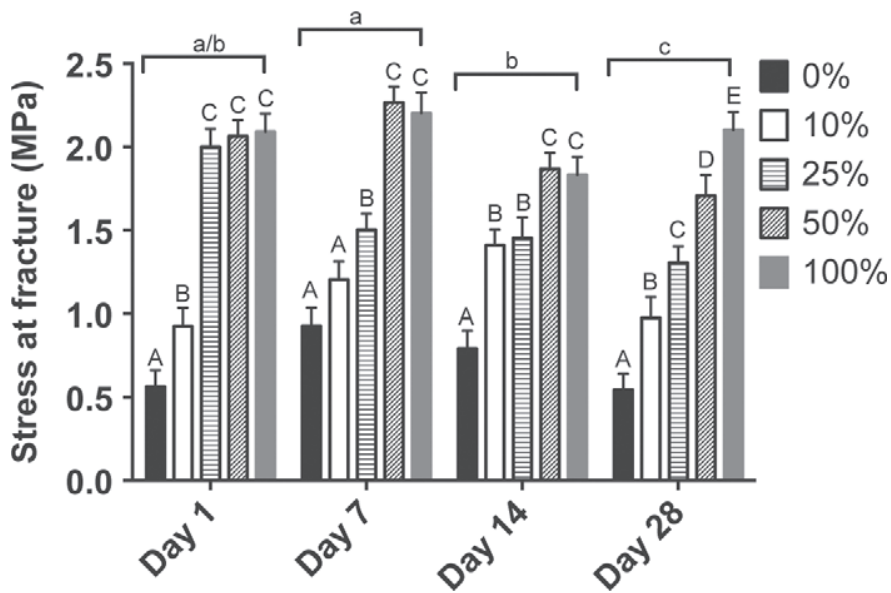

Figure 5. Stress at fracture $(\mathrm{MPa})$ of butter-like emulsions after 1, 7, 14, and $28 \mathrm{~d}$ of storage. Emulsions were made from butter grains mixed with 10, 25, and 50\% anhydrous milk fat (AMF), respectively; 0 and $100 \%$ AMF were used as references. The error bars represent the standard error. Lowercase letters indicate difference between days of measurement; uppercase letters indicate differences between samples within the same day of measurement.

complex rheological and textural behavior of butter-like emulsions during storage. Those findings highlight the importance of using more than one parameter when studying the textural characteristics of milk fat-based products.

\section{CONCLUSIONS}

The presence of butter grains accelerated formation of a continuous crystal network. The elastic modulus was affected by the amount of butter grains, but not by storage time. Increasing the fraction of butter grains decreased the hardness of butter-like emulsions. The amount of butter grains and storage time together affected the solid fat content.

\section{ACKNOWLEDGMENTS}

The authors thank Arla Foods (Viby J, Denmark), the Danish Dairy Research Foundation (Viby J, Denmark), the Danish Food Industry Agency under the Ministry of Food, Agriculture and Fisheries (Copenhagen, Denmark; grant no. 3414-09-02406), and Food Denmark (Frederiksberg, Denmark) for financial support of this project.

\section{REFERENCES}

Alexa, R. I., J. S. Mounsey, B. T. O'Kennedy, and J. C. Jacquier. 2010. Effect of $\kappa$-carrageenan on rheological properties, microstructure, texture and oxidative stability of water-in-oil spreads. Food Sci. Technol. 43:843-848.
Buldo, P. 2013. Crystallization of fat in and outside milk fat globulesEffect of processing and storage conditions. $\mathrm{PhD}$ Thesis. Aarhus University, Viborg, Denmark.

Buldo, P., and L. Wiking. 2012. The role of mixing temperature on microstructure and rheological properties of butter blends. J. Am. Oil Chem. Soc. 89:787-795.

Buldo, P., and L. Wiking. 2013. Microstructure and material properties of milk fat systems during temperature fluctuations. Food Biophys. 8:262-272. http://dx.doi.org/10.1007/s11483-013-9299-y.

Deffense, E. 1993. Milk-fat fractionation today: A review. J. Am. Oil Chem. Soc. 70:1193-1201.

Fredrick, E., D. Van de Walle, P. Walstra, J. H. Zijtveld, S. Fischer, P. Van der Meeren, and K. Dewettinck. 2011. Isothermal crystallization behaviour of milk fat in bulk and emulsified state. Int. Dairy J. 21:685-695.

Haighton, A. J. 1963. Die Konsistenz von Margarine und Fetten. Fette Seifen Anstrichm. 65:479-482.

Herrera, M. L., and R. W. Hartel. 2000. Effect of processing conditions on physical properties of a milk fat model system: Rheology. J. Am. Oil Chem. Soc. 77:1189-1195.

IDF. 1993. Dried milk and cream determination of water content. Provisional Standard 26A. International Dairy Federation (IDF), Brussels, Belgium.

Juriaanse, A. C., and I. Heertje. 1988. Microstructure of shortenings, margarine and butter-A review. Food Microstruct. 7:181-188.

Lopez, C., C. Bourgaux, P. Lesieur, S. Bernadou, G. Keller, and M. Ollivon. 2002. Thermal and structural behavior of milk fat. 3. Influence of cooling rate and droplet size on cream crystallization. J. Colloid Interface Sci. 254:64-78.

Lopez, C., C. Bourgaux, P. Lesieur, and M. Ollivon. 2007. Coupling of time-resolved synchrotron X-ray diffraction and DSC to elucidate the crystallisation properties and polymorphism of triglycerides in milk fat globules. Lait 87:459-480.

Lopez, C., F. Lavigne, P. Lesieur, C. Bourgaux, and M. Ollivon. 2001a. Thermal and structural behavior of milk fat. 1. Unstable species of anhydrous milk fat. J. Dairy Sci. 84:756-766

Lopez, C., F. Lesieur, P. Bourgaux, G. Keller, and M. Ollivon. 2001b. Thermal and structural behavior of milk fat. 2. Crystalline forms obtained by slow cooling of cream. J. Colloid Interface Sci. 240:150-161.

Michalski, M. C., M. Ollivon, V. Briard, N. Leconte, and C. Lopez. 2004. Native fat globules of different sizes selected from raw milk: Thermal and structural behavior. Chem. Phys. Lipids 132:247261

Mortensen, B. K., and H. Danmark. 1982. Consistency characteristics of butter. Milchwissenschaft 37:530-532.

Mulder, H., and P. Walstra. 1974b. Structure and texture of butter. Pages 246-281 in The Milk Fat Globule: Emulsion Science as Applied to Milk Products and Comparable Foods. 1st ed. Pudoc, Wageningen, the Netherlands.

Pothiraj, C., R. Zuñiga, H. Simonin, S. Chevallier, and A. Le-Bail. 2012. Methodology assessment on melting and texture properties of spread during ageing and impact of sample size on the representativeness of the results. J. Stored Products Postharvest Res. $3: 137-144$.

Rønholt, S., J. J. K. Kirkensgaard, K. F. Høyer, K. Mortensen, and J. C. Knudsen. 2014a. Effect of capacity, rotational speed and storage on crystallization and rheological properties of puff pastry butter. J. Am. Oil Chem. Soc. 91:29-38. http://dx.doi.org/10.1007/ s11746-013-2353-6.

Rønholt, S., K. Mortensen, and J. C. Knudsen. 2013. The effective factors on the structure of butter and other milk fat-based products. Compr. Rev. Food Sci. Food Saf. 12:468-482.

Rønholt, S., K. Mortensen, and J. C. Knudsen. 2014b. Small deformation rheology for characterization of anhydrous milk fat/rapeseed oil samples. J. Texture Stud. http://dx.doi.org/10.1111/ jtxs.12048. In press.

Rønholt, S., J. J. K. Kirkensgaard, K. Mortensen, and J. C. Knudsen. 2014c. Effect of cream cooling rate and water content on butter microstructure during four weeks of storage. Food Hydrocoll. $34: 169-176$. 
Rønholt, S., J. J. K. Kirkensgaard, T. B. Pedersen, K. Mortensen, and J. C. Knudsen. 2012. Polymorphism, microstructure and rheology of butter: Effects of cream heat treatment. Food Chem. 135:1730-1739.

ten Grotenhuis, E., G. A. van Aken, K. F. van Malssen, and H. Schenk. 1999. Polymorphism of milk fat studied by differential scanning calorimetry and real-time x-ray powder diffraction. J. Am. Oil Chem. Soc. 76:1031-1039.

Tomaszewska-Gras, J. 2012. Detection of butter alteration with water using differential scanning calorimetry. J. Therm. Anal. Calorim. 108:433-438

van den Tempel, M. 1958. Rheology of plastic fats. Rheol. Acta $1: 115-118$
Walstra, P. 2003. Crystallization. Pages 517-576 in Physical Chemistry of Foods. 1st ed. Marcel Dekker, New York, NY.

Walstra, P., and E. C. H. Van Beresteyn. 1975. Crystallization of milk fat in the emulsified state. Neth. Milk Dairy J. 29:35-65.

Wright, A., M. G. Scanlon, R. W. Hartel, and A. G. Marangoni. 2001. Rheological properties of milkfat and butter. J. Food Sci. $66: 1056-1071$.

Wright, A. J., R. W. Hartel, S. S. Narine, and A. G. Marangoni. 2000 The effect of minor components on milk fat crystallization. J. Am. Oil Chem. Soc. 77:463-465. 